\section{Canadian Food Studies}

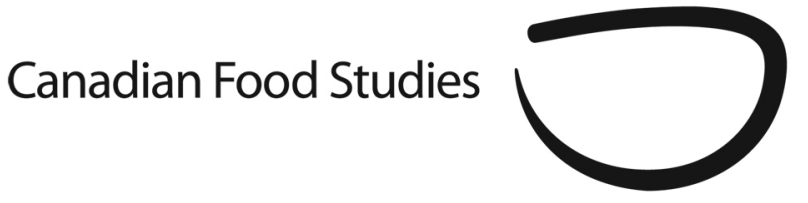

La Revue canadienne des études sur l'alimentation

\title{
Exhibit Review
}

\section{Hedonistika-Montreal \\ Natalie Doonan, Ken Gregory, Stefani Bardin, Simon Laroche and David Szanto. (2014). In International Digital Arts Biennal. Curators Simon Laroche \& Jane Tingley. Montreal, Quebec: Musée D'art Contemporain De Montréal, May 23-30th 2014.}

\section{Review by Pamela Honor Tudge (Concordia University)}

When food, art, and machines clash in a gallery you have Hedonistika. Part food and part robotic exhibition curators Simon Laroche and Jane Tingley tackle the connections between food and technology with the aesthetics of digital art. On offer was a 3D printer providing you with an edible momento mori, a screening of a human GI tract digesting processed food, and a robot that feeds willing visitors. The three installations were created across three teams composed of food scholars, artists, and roboticists.

Hedonistika-Montreal was presented at the Musée d'art contemporian (MAC) during the BIAN (International Digital Arts Festival). Hedonistika-Montréal was invited to build on the festival's theme Physical/ité. In this two-part theme 'physical and physicalité, the festival explored the increasingly complex connections between humans and machines with the practice of visualizing the invisible. Though food is at once a material and a bodily experience ripe for making visible, Hedonistika was the only BIAN exhibit to use food as a mode for interrogation, providing a unique space for expressing food issues and conveying the festival's theme.

The Bliss Point by Natalie Doonan, a food scholar and artist, and Ken Gregory, a robotics artist, focused on the production and consumption of sugar. The most conspicuous piece in this installation was the 'homemade' 3D printer operated by the two artists dressed in white lab coats. The printer constructed sweet and colorful faces, representing a 'candy factory'. At the candy factory, visitors' heads were scanned into a computer using facial recognition software and the 3D printer produced a replica of the scanned face in a sugar and food coloring mix. According to the two artists, the replicas were a memento mori, a symbolic reminder of our own mortality in the form of a sugary death mask - and perhaps sugar's contribution to this end. Alongside the 3D printer, exhibit cases-modeled after specimen displays in a $19^{\text {th }}$ century 
museum - presented physical pieces of sugar in its different forms alongside information on the history of sugar cane, highlighting the colonial context and health concerns around obesity and diabetes. The intent with the installation is to contrast our love of sugar as a source of pleasure against corporate manipulation that pushes sugar more and more into our bodies. The candy factory, with lab coats and machines lured me in immediately; the display cases took more effort to engage with despite the well-placed information. Like so many others in our society, I was more drawn to the pleasure side of sugar.

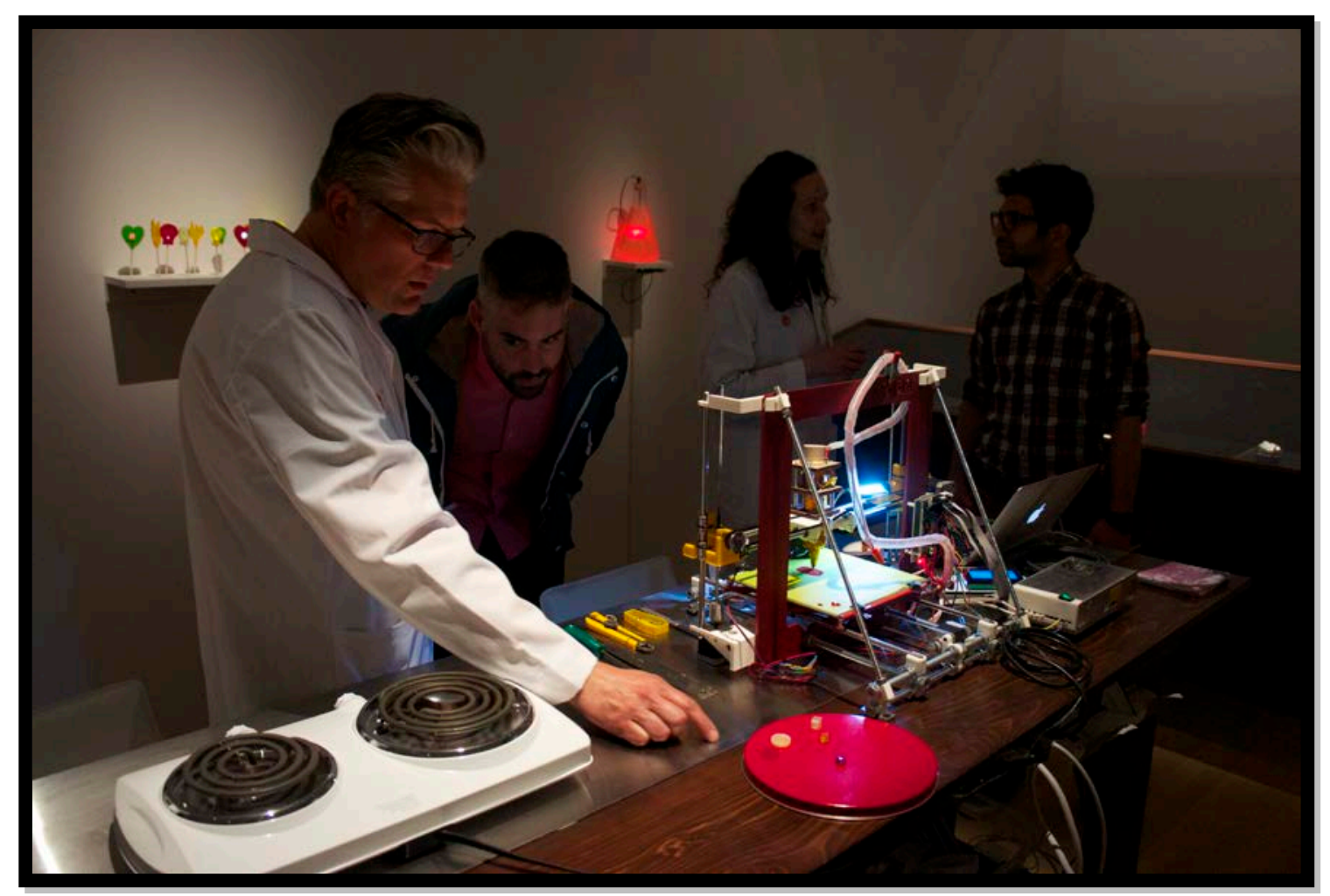

Picture 1: The Bliss Point, Photo by Jane Tingley

M2A: The Fantastic Voyage by artist Stefani Bardin and gastroenterologist Dr. Braden Kuo dealt with the difference between processed foods and whole foods. A monitor displayed images of the inside of a gastrointestinal tract through the use of a Pill Cam - a wireless device that, once swallowed, transmits a live video feed of the digestion process. In this case, a volunteer consumed store-bought Gatorade, ramen, and gummy bears and later a homemade version of each. At the exhibition, the monitor split the screen to contrast the recorded videos, showing the GI tract digesting processed foods versus whole foods. The implications of the two images is probably much more evident to a trained doctor or gastroenterologist—such as Dr. Kuo-yet even my naive eye could detect that there was a difference. Supporting the differences between the two digestive processes was the impressive display of specimen jars lined up the gallery wall. Each jar contained an ingredient. Obvious was the considerably longer line of jars containing the processed ingredients. From the gallery floor, peering up, I saw the jars were filled with many different brightly colored powdered substances. Contrasting with this line was 
the whole food ingredients, with only a few jars and more recognizable ingredients. Although concerns around processed foods are not new, within a gallery space the exhibit offers something beyond information, a potent visual take-away.

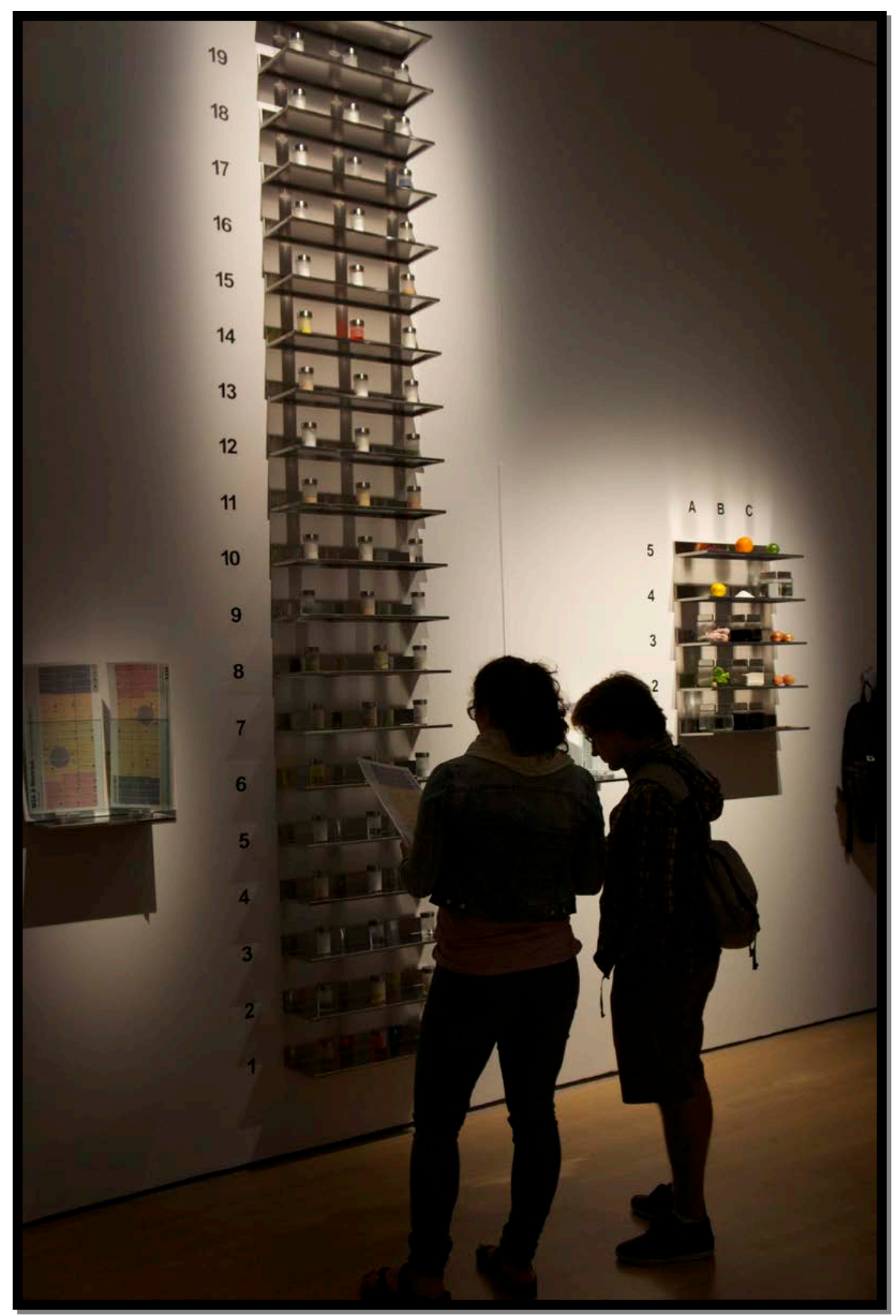

Picture 2: M2A: The Fantastic Voyage, Photo by Jane Tingley 


\section{Orchestrer la perte/Perpetual Demotion by robotics artist Simon Laroche and food scholar} and artist David Szanto features a shiny robot, spoons filled with different kinds of paste, and a human 'slave'. A 'slave' as the artists label their human helper was an unnamed and silent woman, who's function was to serve the robot spoons of paste for each new participant. The robot was attached to the wall and equipped to recognize your facial features, pick up a spoon and move the spoon of paste towards your mouth. The robot had a video camera to live stream or record the interaction from the robot's perspective as it fed the brave gallery visitors. The pastes were administered with no choice and without any ingredient list. I was surprised at the opening night, how many people lined up to try the paste. My own attempt took a couple tries as my apprehension to what I was about to taste caused the robot to miss my mouth—not unlike a parent missing a child's closed mouth. Finally, I gave in and tasted an unexplainable mix of sweet and salty with a little bit of textured food substance. The ingredient list was unknown to visitors - it was necessary to completely succumb to the robot to find out what was on offer. Hence, the installation's name refers to the interaction as a form of human demotion-an unsettling loss of control to a non-human caregiver while receiving potentially nourishing food.

Picture 3: Orchestrer la perte/Perpetual Demotion, Photo by Lora Baiocco

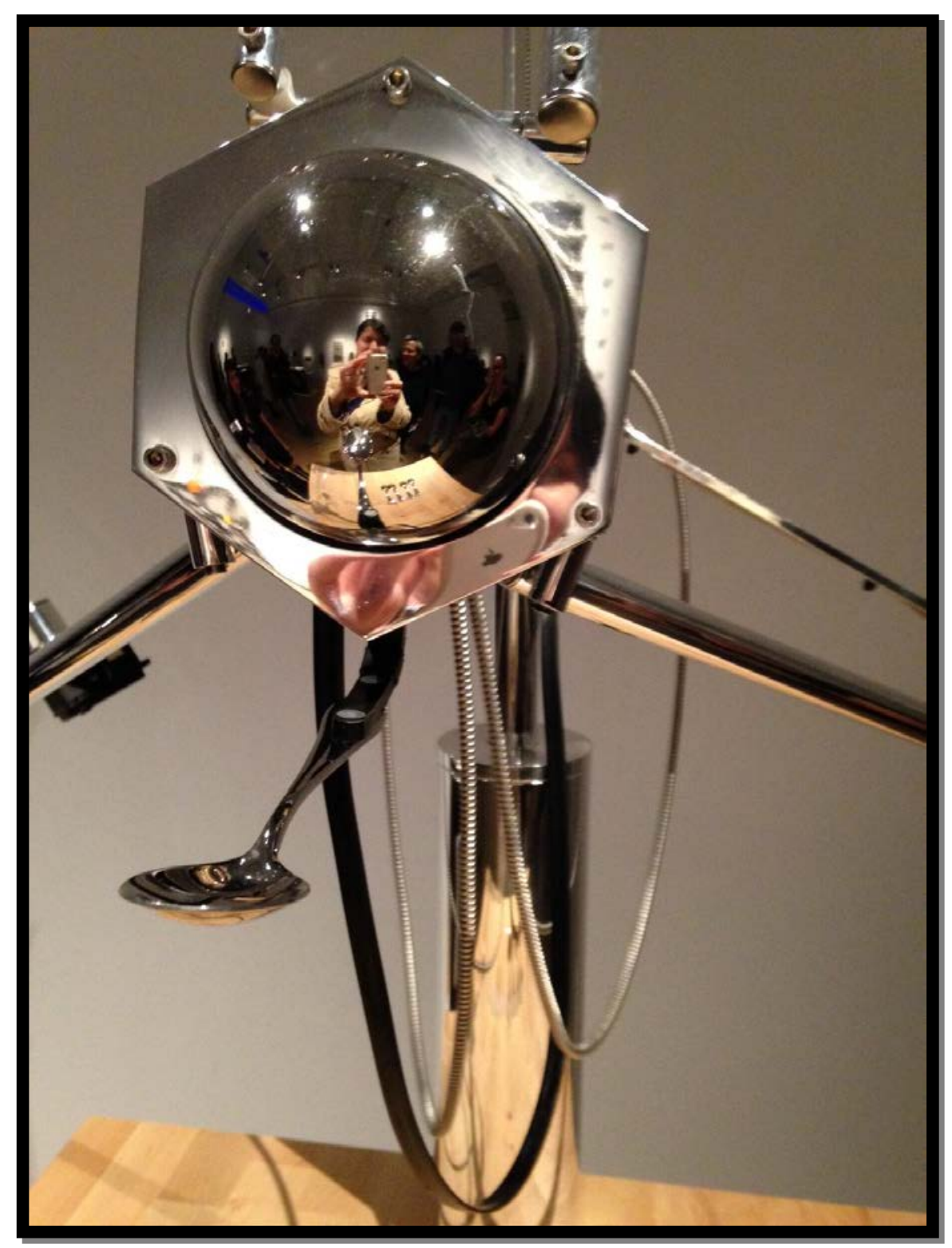


Hedonistika-Montreal was one of those hybrid moments that food studies scholars need to take note of as we look for innovative ways to develop and communicate our work. From an art perspective, this exhibit moved beyond the visual to an experiential event-illuminating the prospective physical nature of technology and digital art. For food scholars and researchers the exhibit presented a refreshing way to untangle the messiness of food-placing food within technology and then pulling it all apart again.

Stay tuned as Hedonistika organizers take the festival to new locations with different teams; hence there is much more to come for this robotic, food, technology art mash-up. For more information check out: http://bianmontreal.ca/en/calendar/hedonistika-montreal and http://www.hedonistika.com/

Pamela Honor Tudge is currently at Concordia University in the Interdisciplinary program as a PhD student in Fine Arts. Her focus currently is on food movements and the built environment in Canada. Pamela holds an MA from UBC, where she completed a thesis that examined the use of media with small-scale farmers. She has worked and researched in food studies and environmental studies for over 12 years, focusing in climate change policy, local food systems, Indigenous food systems and DIY media and mapping. 